\title{
A New Record: Incidence of Arbuscular Mycorrhizal Fungi (AMF) in Eleocharis konkanensis an Endemic Sedge of Maharashtra (India)
}

\author{
Vishal R. Kamble ${ }^{1 *}$, Sonali S. Lanjekar ${ }^{1,2}$, \\ Yadvendradatta R. Yadav', Meghana M. Kolekar ${ }^{1}$ and Arun N. Chandore ${ }^{2}$
}
${ }^{1}$ Mycorrhizal Research Laboratory, Department of Botany, Bhavan's College Andheri (West), Mumbai (MS) 400058 India
${ }^{2}$ Department of Botany, Abasaheb Marathe Arts and New Commerce, Science College, Rajapur- 416 702, District-Ratnagiri, MS, India

*Corresponding author

\section{A B S T R A C T}

\begin{tabular}{|l|}
\hline K ey w or d s \\
Acaulosporaceae, \\
Arbuscular \\
Mycorrhizal Fungi \\
(AMF), Cyperaceae, \\
Eleocharis \\
konkanensis, \\
Endemic plant, \\
Lateritic rocky \\
plateaus \\
\hline Article Info \\
\hline Accepted: \\
18 April 2018 \\
Available Online: \\
10 May 2018 \\
\hline
\end{tabular}

Family Cyperaceae, members are commonly known as sedges. This family has ambiguity about mycorrhizal or non-mycorrhizal nature. So far, many sedges have been investigated globally for mycorrhizal occurrence interest. However, a sedge genus, Eleocharis has been not paid more attention for mycorrhizal investigations. Present work is the first attempt to evaluate mycorrhizal status in a recently discovered endemic sedge species: Eleocharis konkanensis Chandore, Borude, Kambale \& S.R. Yadav which grows in a Lateritic rocky plateaus habitat. This study makes a new report on mycorrhization in an endemic sedge: E. konkanensis The roots of E. konkanensis from lateritic platue are microscopically examined for colonization of AMF. The study revealed that the roots of all the plants were colonized in the range of $21-98 \%$ by AM fungal components. Overall colonization percentage $(O C p)$ in E. konkanensis is 56.55. Analysis of mychorrhizal roots suggests there is great variation found in occurrence intensity $(O I)$ expression for vesicles

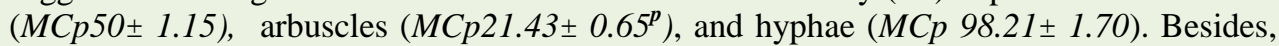
extraradical and intraradical spores of AMF have been recorded to roots. During present work, 12 AMF species belonging to four Glomeromycota families are recorded in association with E. konkanensis. These AMF species are viz., Aculospora dilatata, A. scrobiculata, A. spinosa., A. sporocarpa, Acaulospora spp, A. tuberculata; Diversispora epigaea; Scutellospora arenicola, Glomus albidum, G. ambisporum, G macrocarpum and Septoglomus constrictum. Thus, E. konkanensis is the first representative of genus Eleocharis ever studied by any Indian mycologist with reference to root colonization followed by spore's identification of AMF at species level. Till the present work, no data was available on AMF species of genus Eleocharis. Hence, E. konkanensis is proposed here as the first representative of genus Eleocharis ever studied by any mycologist. Based on the relative abundance and spore density the native AMF species of endemic $E$. konkanensis are viz., Diversispora epigaea, Aculospora dilatata and Aculospora scrobiculata. Finally, on the basis of in-depth analysis we propose that Eleocharis konkanensis an endemic sedge of Maharashtra is a new mycorrhizal plant to the science. 


\section{Introduction}

The members of the Cyperaceae are commonly known as sedges. The genus Eleocharis Brown is distributed worldwide. According recent checklist of Cyperaceae (Govaerts et al., (2016), Eleocharis comprises about 300 species at global data. As far as concern with present context, till date 26 species of Eleocharis are known to India. It includes E. setifolia (A. Rich) Raynal which is recorded for India by Wadoodkhan (2015); three new species recently described for Indian states are viz., E. khandwaensis Mujaffar, Chandore and S.R. Yadav from Madhya Pradesh (Mujaffar et al., 2014), E. konkanensis Chandore, Borude, Kambale and S.R. Yadav (Chandore et al., 2016) and E. neglecta Borude, Chandore, Gholave and S.R. Yadav (Borude et al., 2016) from Maharashtra.

Geographically, Eleocharis konkanensis distributed endemically at 200-300 ft from MSL on Low level Ferricrete (LLF)- Lateritic rocky plateaus of Konkan region specifically at Sindhudurg and Ratnagiri district of Maharashtra in India.

Several species of Eleocharis are investigated for their allelopathic effects on other aquatic and wetland plants (Wooten and Elakovich 1991; Pedersen, 2002).

Although it is assumed that, Cyperaceae members are lacked with mycorrhizal association or it is very rare (Hirsch and Kapulnik 1998); however, several reports have produced supportive records for mycorrhization is predominantly of AMF type in sedges (see Harley and Harley 1987a; Tester et al., 1987). However a sedge genus Eleocharis has been not paid more attention for mycorrhizal investigations. Because, arbuscular mycorrhizal fungi (AMF) are a ubiquitous soil-inhabiting obligate biotrophic root fungi (Smith and Read, 2008) and they plays significant role in ecosystem functioning.

The AMF diversity data relies primarily in studies performed in natural ecosystems. Nevertheless, little is known about AMF diversity in extreme human-impacted ecosystems such as Lateritic rocky plateaus associated ephemerals.

Review of documents on AMF of Eleocharis species for last seven decades (Dowding, 1959 to de la Providencia et al., (2015) including contribution of Muthukumar (2004) and Hossler (2010) showed that (Table 1), genus Eleocharis comprises three categories of plant species such as mycorrhizal, non-mycorrhizal and mycorrhizal as well as non-mycorrhizal. Eleven species of Eleocharis were reported as mycorrhizal viz., E. acutangula, $E$. atropurpurea, E. dulcis, E. geniculata, E. obtusa, E. ovata, E. palustris, E. pusilla, E. quinqueflora, Eleocharis sp., and Eleocharis spp. Whereas, non-mycorrhizal Eleocharis species were viz., E. aff. pachycarpa, E. congesta, E. elliptica, E. erythropoda, E. geniculata, E. quinqueflora, E. scheuchezeri, Eleocharis sp., E. tenius, E. triste, and E. vaginatum (Table 1). From this survey it is evident that, two species viz., E. geniculata and E. quinqueflora were recorded as dual performers $\mathrm{i}$ e mycorrhizal as well as nonmycorrizal. Thus out of twenty Eleocharis species about $50 \%$ are known to be distinctly mycorrhizal and rest is non-mycorrhizal.

All the 20 species so far investigated were associated with wetland ecosystem at global scenario. Present work is the first attempt to evaluate mycorrhizal status in a recently discovered E. konkanensis grown in Lateritic rocky plateaus habitat. This study makes a new report on mycorrhization in an endemic sedge E. konkanensis. 


\section{Materials and Methods}

\section{Site description and sample collection}

Sampling was performed at LLF-Lateritic rocky plateaus of Hativale, Abasaheb Marathe College Campus, Vikhare Gothane, $\left(16.6572^{0}\right.$ North and $73.5211^{\circ}$ East) $12 \mathrm{~km}$ from Rajapur which falls under Ratnagiri district. $E$. konkanensis samples were collected during July 2016 (SSL and MMK) and identification was validated by ANC. The dry preservation is deposited at Botany department herbarium, BCA (Figure 1A).

E. konkanensis is a small, perennial ephemeral herb, grows along the edges of natural ponds, on roadside and on the open places of lateritic plateaus having considerably less soil layer. As, it grows in association with other ephimerals such as: Cyperus pulchellus and Eleocharis atropurpurea, Habenaria grandifloriformis, Utricularia reticulata and Trithuria konkanensis. Therefore roots excavation of E. konkanensis and its soil collection was done randomly from about 2530 such a plants where associating ephimerals were less crowded. This precaution was taken to avoid unwanted collection of AMF biota of unwanted vegetation and thereby to prevent misleading results on AMF spores. Altogether, around $250 \mathrm{~g}$ soil was randomly collected for AMF spore extraction procedure and to determine the soil properties.

The plants along with the soil samples and roots were collected in different collection bags and transported from field to laboratory which immediately refrigerated at $4^{\circ} \mathrm{C}$ subsequent to arrival. The roots were processed immediately. All the rhizosphere soil samples were homogenized prior to remove coarse roots segments, stones and adhered particles through sieving procedure (2 $\mathrm{mm}$ mesh size). Subsamples of soil were air dried and used for estimation of physicochemical properties

\section{Physicochemical parameters of soil:}

Physicochemical parameters were tested for soil: i) texture, moisture (Jackson, 1967); ii) pH (van Reeuwijk, 2002); iii) organic carbon (Walkley and Black, 1938); iv) carbonate (Piper, 1966) and available phosphorus (Olsen et al., 1954).

\section{Status of AM fungal colonization in roots}

It was determined by assessing roots for percentage of colonization and occurrence intensity of three mycorrhizal components as given below:

\section{Percentage colonization}

The randomly selected and stained 100 root segments of of E. konkanensis were observed under a light microscope and subjected to intercept method (Brundrett, et al., 1996), AMF colonization percentage,(Phillips and Hayman 1970). The overall colonization percentage $(O C P)$ by AMF was calculated on the basis of observed values for mean colonization percentage (MCp) of three component i) vesicles $(V)$, ii) arbuscules $(A)$ and iii) hyphae $(H)$. The occurrence of other fungal endophytes $(\mathrm{Ofe})$, such as dark septate endophytes (DSE) was also screened. microscopically.

\section{Occurrence intensity}

All the three components of AMF were interpreted for occurrence intensity under categories such as, poor (1-25\%), moderate (25-50\%), good $(50-75 \%)$ and excellent $(>75 \%)$ which was denoted as ' $p, m, g$ and $e$ ' respectively. To interpret occurrence intensity $(O I)$ of fungal structures, mean colonization percentage $(M C p)$ for each fungal structure $V$, $A$ and $H$ was determined separately. Finally pattern of AMF colonization for $E$. konkanensis was determined. Any other special structure of mycorrhizal colonization 
(Smc) if present in root piece was also recorded.

\section{AM fungal spore extraction}

AMF spores were extracted by following sieving and decanting technique of Gerdemann and Nicolson (1963) with limited quantity of rhizospheric soil $(10 \mathrm{~g})$. Total spore number was estimated following by Gaur and Adholeya (1994). Apparently healthy spores were counted under stereomicroscope (Olympus 003421) and examined under Binocular Light microscope using different objectives like 10x, 40x and 100x. Slides were digitally documented with the help of Canon IXUS 155 Camera.

\section{AM fungal species identification}

Taxonomical placements of AM fungal spores and sporocarps up to species level were done using bibliographies by Schenk and Perez (1990). The identification is purely based on the synaptic keys (Hall and Fish, 1979; Pacioni, 1992) and also after consulting AMF species descriptions provided by International Culture Collection of Vesicular and Arbuscular Endomycorrhizal Fungi [http://invam.caf.wvu.edu/Myc_Info/Taxonom $\mathrm{y} /$ species.htm]. The species codes were followed after Schenk and Perez (1990).

The voucher slides containing the isolated spore specimens were assigned accession codes ' $B C A: M H_{S S L}{ }^{n}$ ' [where, BCA:MH is Bhavan's College Andheri: Mycological Herbarium; SSL: initials of second Author and ' $n$ ' is accession number assigned]. All the slides and corresponding photo-micrographic plates have been deposited in the slide collection section of Mycorrhizal Research Laboratory of Department. The Spore density (S) was considered as the number of spores in $10 \mathrm{~g}$ soil. Relative abundance (RA) value for AMF species (RAspp) was equivalent to the spore percentage of a species (Dandan and Zhiwei, 2007). Similarly, RA of AMF family (RAfam) was considered as spore percentage of a family. Based on RA and S values ( $R A s p p$ $>6 \%)$ and spore density ( $\mathrm{S} \geq 7$ spores) the dominant AMF species were determined. Similarly dominating Glomeromycota families of $E$. konkanensis rhizospere were determined $($ RAfam $>40 \%)$ and spore density $(\mathrm{S} \geq 10$ spores).

The standard errors of means were statistically analyzed for percentage colonization, spore density and relative abundance of AMF species by using Microsoft excel 2010.

\section{Results and Discussion}

Physico-chemical parameters of soil of $\mathbf{E}$. konkanensis

Nature of soil needed for each plant and its rhizospheric microbes is varies from species to species and hence for habitat restoration and conservation program the soil properties should be taken into consideration. The soil of study area is lateritic and reddish due to excess natural iron content. Soil sampled from $E$. konkanensis rhizosphere has a relatively loose texture and its characteristics are shown in Table 2. These soils often have up to $40 \%$ gravel and slightly acidic with $\mathrm{pH}$ 6.4. Organic Carbon $(5.70 \%)$ and Organic matter $(9.80 \%)$ calculated is higher in the topsoil of E. konkanensis Whereas, Carbonate content recorded is quite higher $\left(19.09 \pm 0.01 \mathrm{mg} \cdot \mathrm{kg}^{-1}\right)$; while phosphorus content is poor $1.04 \pm$ $0.02 \mathrm{mg} . \mathrm{kg}^{-1}$

\section{Percentage colonization and occurrence intensity of AMF in roots of E. konkanensis}

Based on tabulated references (Table 1), out of twenty Eleocharis species nine were either distinctly mycorrhizal or non-mycorrhizal, and remaining two were of dual nature showing 
mycorrhizal as well as non-mycorrhizal association. All the earlier known mycorrhizal Eleocharis species were reported on the basis of interception method only and not by AMF spores identification technique. In present work we have assessed the mycorrhizal nature of endemic sedge E. konkanensis based on both root interception method and AMF spores extraction followed by identification up to species level.

\section{Percentage colonization}

The roots of E. konkanensis from lateritic platue were microscopically examined for presence of AMF (Table 3). In present assessment, roots of E. konkanensis were assessed for presence of AMF colonization (Table 3) and denoted by $M C p$ i. e. mean colonization percentage for individual components. The study revealed that the roots of all the plants were colonized in the range of $21-98 \%$ by AM fungal components. The degree of AMF components colonization was found varied i. e. vesicles $50 \%$ arbuscules $21.43 \%$ and hyphae $98.21 \%$. However, overall colonization percentage $(O C p)$ in $E$. konkanensis was 56.55 .

Table.1 Tabulated review of documents* on mycorrhizal incidence in genus Eleocharis

\begin{tabular}{|c|c|c|c|c|c|}
\hline \multirow{2}{*}{\multicolumn{2}{|c|}{ Eleocharis species }} & \multicolumn{3}{|c|}{ Mycorrhizal status } & \multirow[t]{2}{*}{ References } \\
\hline & & $\mathbf{M}$ & NM & $\mathbf{P R}(\mathrm{cm})$ & \\
\hline 1. & E. acutangula & $\sqrt{ } \mathbf{M}$ & - & 0.1 & $M^{16,18,19,22,29}$ \\
\hline 2. & E. aff. pachycarpa & - & $\sqrt{ } \mathrm{NM}$ & - & $\mathrm{NM}^{12}$ \\
\hline 3. & E. atropurpurea & $\sqrt{ } \mathbf{M}$ & - & 0.23 & $\mathrm{M}^{2}$ \\
\hline 4. & E. congesta & - & $\sqrt{\mathrm{NM}}$ & 0 & $\mathrm{NM}^{6}$ \\
\hline 5. & E. dulcis & $\sqrt{ } \mathrm{M}$ & - & - & $\mathrm{M}^{21}$ \\
\hline 6. & E. elliptica & - & $\sqrt{ } \mathrm{NM}$ & 0 & $\mathrm{NM}^{30}$ \\
\hline 7. & E. erythropoda & - & $\sqrt{ } \mathrm{NM}$ & 0 & $\mathrm{NM}^{27}$ \\
\hline 8. & E. geniculata & $\sqrt{\mathrm{M}}$ & $\sqrt{ } \mathrm{NM}$ & 0 & $\mathrm{M}^{8,29} ; \mathrm{NM}^{16,21,25}$ \\
\hline 9. & E. obtusa & $\sqrt{ } \mathbf{M}$ & - & $0-0.75$ & $\mathrm{M}^{10,15}$ \\
\hline 10. & E. ovata & $\sqrt{ } \mathbf{M}$ & - & $0-0.9$ & $M^{8,29}$ \\
\hline 11. & E. palustris & $\sqrt{ } \mathrm{M}$ & - & $0-0.75+$ & $M^{1,3,5,13,14,15,16,24,29}$ \\
\hline 12. & E. pusilla & $\sqrt{ } \mathbf{M}$ & - & $0-0.56$ & $M^{7,16}$ \\
\hline 13. & E. quinqueflora & $\sqrt{ } \mathbf{M}$ & $\sqrt{ } \mathrm{NM}$ & + & $\mathrm{M}^{11,16} ; \mathrm{NM}^{13,14,29}$ \\
\hline 14. & E. scheuchezeri & - & $\sqrt{ } \mathrm{NM}$ & - & $\mathrm{NM}^{4,16,28}$ \\
\hline 15. & Eleocharis sp. & $\sqrt{ } \mathrm{M}$ & - & - & $M^{8}$ \\
\hline 16. & Eleocharis sp. & - & $\sqrt{ } \mathrm{NM}$ & - & $\mathrm{NM}^{12}$ \\
\hline 17. & Eleocharis spp. & $\sqrt{ } \mathbf{M}$ & - & $0-0.7$ & $\mathrm{M}^{8}$ \\
\hline 18. & E. tenius & - & $\sqrt{ } \mathrm{NM}$ & 0 & $\mathrm{NM}^{9}$ \\
\hline 19. & E. triste & - & $\sqrt{ } \mathrm{NM}$ & - & $\mathrm{NM}^{4}$ \\
\hline 20. & E. vaginatum & - & $\sqrt{ } \mathrm{NM}$ & - & $\mathrm{NM}^{26}$ \\
\hline \multicolumn{6}{|c|}{$\begin{array}{l}\text { *After analyzing }{ }^{20} \text { Muthukumar }(2004) \text { and }{ }^{15} \text { Hossler }(2010) \\
\text { PR: A proportional range of root length }(\mathrm{cm}) \text { colonized by AMF is provided when available; however, some studies reported only '+, } \\
\text { or '-', so these indicators are also included. }\end{array}$} \\
\hline \multicolumn{6}{|c|}{ 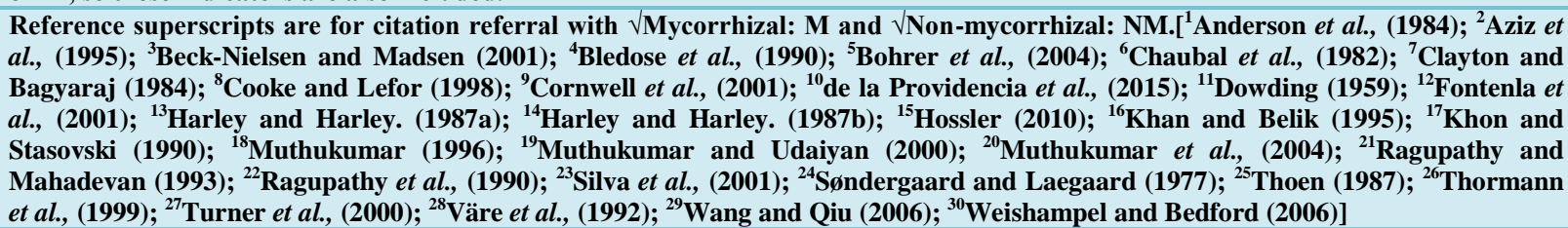 } \\
\hline
\end{tabular}


Table.2 Physicochemical properties of E. konkanensis soil

\begin{tabular}{|c|l|l|}
\hline Sr.No. & \multicolumn{1}{|c|}{ Parameters } & \multicolumn{1}{c|}{ Status } \\
\hline $\mathbf{1 .}$ & Colour & Red \\
\hline $\mathbf{2 .}$ & Soil texture & $\approx 40 \%$ gravel, \\
\hline $\mathbf{3 .}$ & PH & $6.44 \pm 0.02$ \\
\hline $\mathbf{4 .}$ & Organic Carbon & $5.70 \%$ \\
\hline $\mathbf{5 .}$ & Organic Matter & $9.80 \%$ \\
\hline $\mathbf{6 .}$ & Carbonate & $19.09 \pm 0.01 \mathrm{mg} \cdot \mathrm{kg}^{-1}$ \\
\hline $\mathbf{7 .}$ & Phosphorus & $1.04 \pm 0.02 \mathrm{mg} \cdot \mathrm{kg}^{-1}$ \\
\hline
\end{tabular}

$( \pm)$ Standard error of mean

Table.3 Incidence of AMF colonization in roots of E. konkanensis

\begin{tabular}{|c|c|c|c|}
\hline Particulars & \multicolumn{3}{|c|}{ AMF colonization } \\
\hline Fungal structures & Vesicles & Arbuscules & Hyphae \\
\hline МСp (\%) & $50 \pm 1.15^{\mathrm{m}}$ & $21.43 \pm 0.65^{\mathrm{p}}$ & $98.21 \pm 1.70^{\mathrm{e}}$ \\
\hline ОСр (\%) & \multicolumn{3}{|c|}{$56.55 \pm 1.16^{\mathrm{g}}$} \\
\hline OI & Moderate & Poor & Excellent \\
\hline OCI & \multicolumn{3}{|c|}{ Good } \\
\hline Smc Features & \multicolumn{3}{|c|}{ Formation of: $\mathrm{A}, \mathrm{Av}, \mathrm{Ch}, \mathrm{H}, \mathrm{Hc}, \mathrm{ERs}$, IRs \& S (Figure $1 \mathrm{~B}-\mathrm{C}$ ) } \\
\hline Pme & \multicolumn{3}{|c|}{ VAH } \\
\hline Other fungal endophytes & \multicolumn{3}{|c|}{ Ofe-Present: Dsh \& Scl (Figure 1D) } \\
\hline
\end{tabular}

(MCp) mean colonization percentage; (OI)Occurrence intensity [(p) 1-25\%, (m) 25-50\%, (g) 50-75\%, (e)>75\%]; (Smc)Structures of Mycorrhizal colonization [(A) Arbuscules, (Av) Aggregated vesicles, (Ch) Chlamydospore, (H) Hyphae; (H) Hyphal coiling; $(\boldsymbol{E R s})$ Extraradical spore, $(\boldsymbol{I R S})$ Intraradical spore and $(\boldsymbol{S})$ young spore]; $(\boldsymbol{O C I})$ Overall colonization intensity [range of values is same as $\boldsymbol{O I}$ ]; (OCp) Overall colonization percentage; (Pmc) Pattern of Mycorrhizal colonization; (VAH) Vesicular-Arbuscular-hyphal type; (ofe) Other fungal endophytes, $[(\boldsymbol{D s h})$ dark septate hyphae and $(\boldsymbol{S c l})$ sclerotia

Table.4 AMF species associated with E. konkanensis and their spore density (S) and relative abundance (RA)

\begin{tabular}{|c|c|c|c|c|}
\hline \multirow{2}{*}{$\begin{array}{l}\text { Specimen } \\
\text { Accession Code }\end{array}$} & \multirow[t]{2}{*}{ AMF species } & \multirow[t]{2}{*}{$\mathbf{S}$} & \multicolumn{2}{|c|}{ RA } \\
\hline & & & RAspp & $\boldsymbol{R A f m}$ \\
\hline \multicolumn{2}{|r|}{ Family: Acaulosporaceae } & \multicolumn{3}{|c|}{54.901} \\
\hline BCA: $M H_{S S L} 01$ & Aculospora dilatata Morton. & 7 & 13.725 & \multirow[t]{6}{*}{54.901} \\
\hline BCA:MH ${ }_{S S L} 02$ & Acaulospora scrobiculata Trappe & 7 & 13.725 & \\
\hline$B C A: M H_{S S L} 03$ & Aculospora spinosa. Walker and Trappe & 2 & 3.921 & \\
\hline BCA:MH ${ }_{S S L} 04$ & Aculospora sporocarpa Berch & 6 & 11.764 & \\
\hline BCA: $M H_{S S L} 05$ & Acaulospora spp1 & 2 & 3.921 & \\
\hline$B C A: M H_{S S L} 06$ & Aculospora tuberculata Janos and Trappe & 4 & 7.843 & \\
\hline \multicolumn{5}{|c|}{ Family: Diversisporaceae } \\
\hline BCA: $M_{S S L} 07$ & Diversispora epigaea (B.A. Daniels \& Trappe) C. Walker \& A. Schüßler & 9 & 17.647 & 17.647 \\
\hline \multicolumn{5}{|c|}{ Family: Gigasporaceae } \\
\hline BCA:MH ${ }_{S S L} 11$ & Scutellospora arenicola Koske \& Halvorson & 2 & 3.921 & 3.921 \\
\hline \multicolumn{5}{|c|}{ Family: Glomeraceae } \\
\hline BCA:MH ${ }_{S S L} 08$ & Glomus albidum C. Walker \& L.H. Rhodes & 4 & 7.843 & \multirow[t]{4}{*}{23.529} \\
\hline BCA:MH ${ }_{S S L} 09$ & Glomus ambisporum G.S. Sm. \& N.C. Schenck & 1 & 1.960 & \\
\hline$B C A: M H_{S S L} 10$ & Glomus macrocarpum Tul. \& C. Tul. & 6 & 11.764 & \\
\hline BCA:MH ${ }_{S S L} 12$ & Septoglomus constrictum G.A. Silva \& Oehl & 1 & 1.960 & \\
\hline Total & 12 & 51 & 100 & 100 \\
\hline
\end{tabular}


Figure.1 Fig 1A-D Eleocharis konkanensis Chandore, Borude, Kambale and S.R. Yadav and root colonization. Fig 1A Specimen; Fig 1B-C Root colonization showing mycorrhizal components viz. Arbuscules $[A]$, Aggregated vesicles $[A v]$; Chlamydospore $[C h]$; Hyphae $[H]$, Hyphal coiling $[H c]$, Extrararadical spore $[E R s]$; Intrararadical spore $[I R s]$, young spore $[S]$ etc; Fig 1D Root colonization with other fungal endophyte $[O f e]$ components viz., dark septate hyphae $[D s h]$ and Sclerotia $[S c l]$

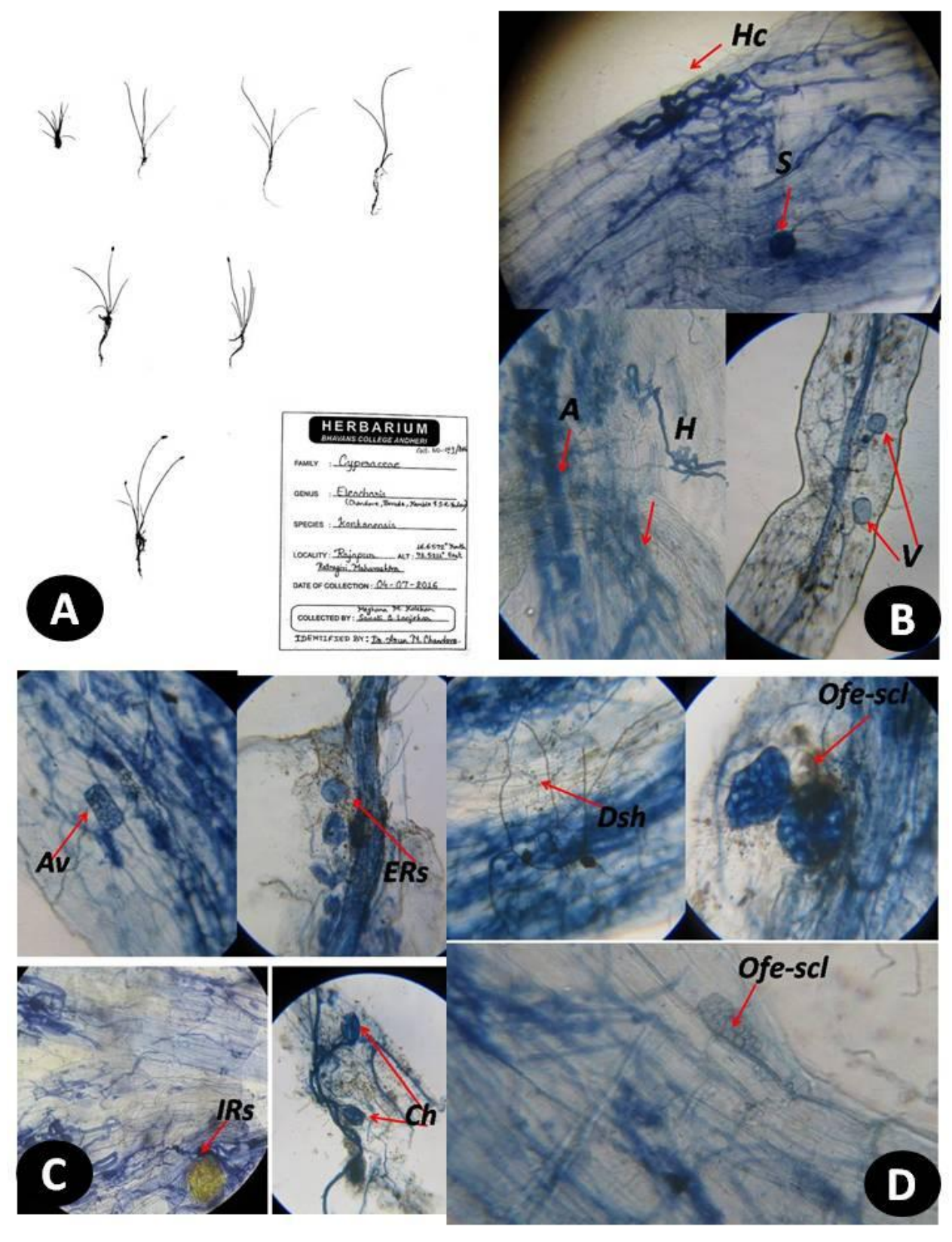

FIGURE 1 
Figure.2A-D. AMF spores associated with Eleocharis konkanensis showing morphotype details. Fig.2A Acaulospora dilatata Morton.; Fig.2B Acaulospora scrobiculata Trappe; Fig.2C Aculospora spinosa Walker and Trappe and Fig.2D Aculospora sporocarpa Berch [Fig.2A-D(a) Spore mounting in different media like water, Melzer's Reagent and PVLG; Fig 2A-C(b) Entire or crushed spore; Fig.2D(b) Crushed spore showing Circatrix (arrow); 2A-D(c) Magnified view showing spore wall and surface details]

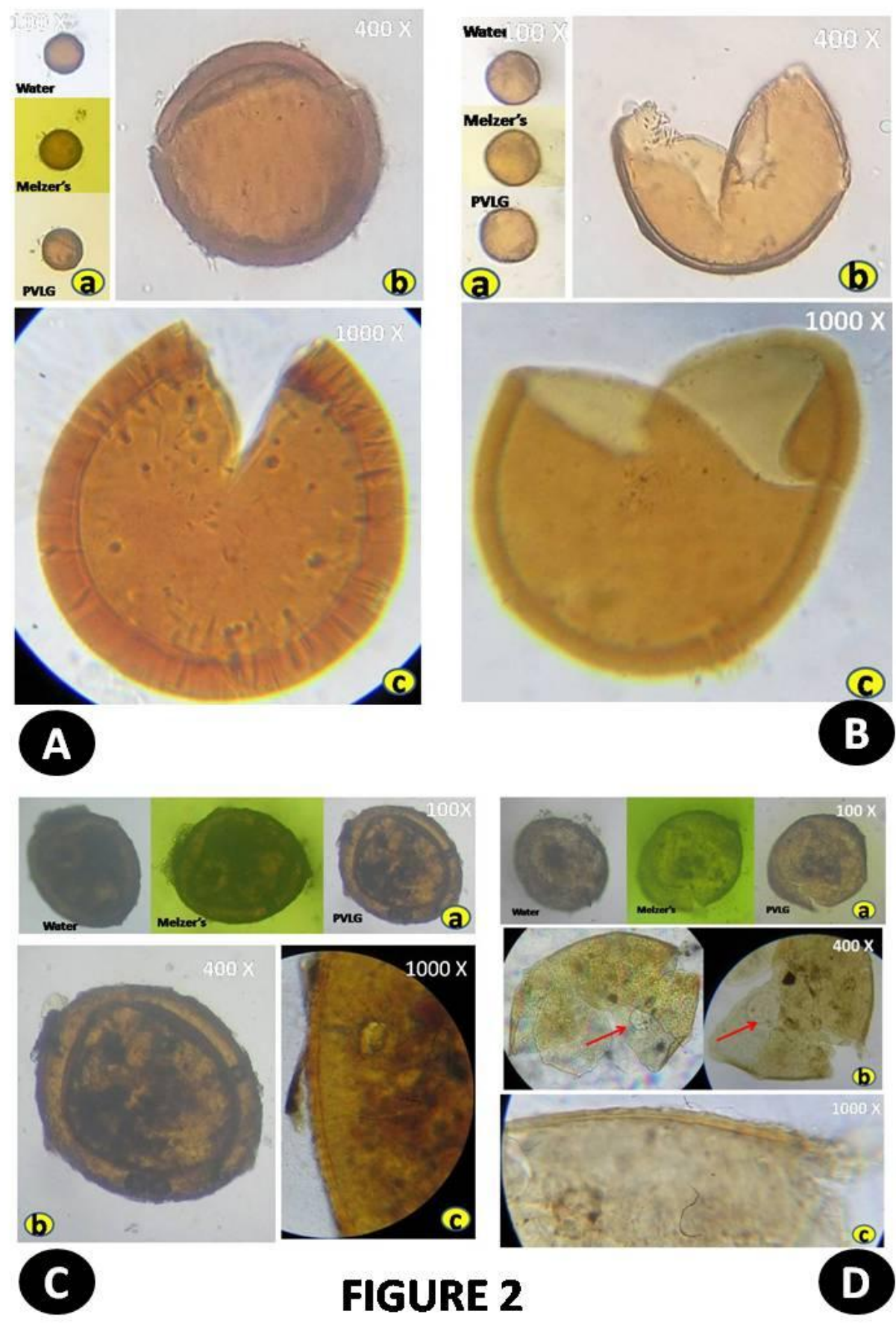


Figure 3A-D. AMF spores associated with Eleocharis konkanensis showing morphotype details. Fig.2A Aculospora spp1; Fig.3B Aculospora tuberculata Janos and Trappe; Fig.3C Diversispora epigaea (B.A. Daniels and Trappe) C. Walker and A. Schüßler and Fig.3D Magnified view of entire spores of (a) Glomus albidum C. Walker and L.H. Rhodes (b) Glomus ambisporum G.S. Sm. and N.C. Schenck; (c) Glomus macrocarpum Tul. and C. Tul. [Fig.3A$\mathrm{C}(\mathrm{a})$ Spore mounting in different media like water, Melzer's Reagent and PVLG; Fig.3A-C(b) Entire or crushed spore; $3 \mathrm{~A}-\mathrm{C}(\mathrm{c})$ Magnified view showing spore wall and surface details.]

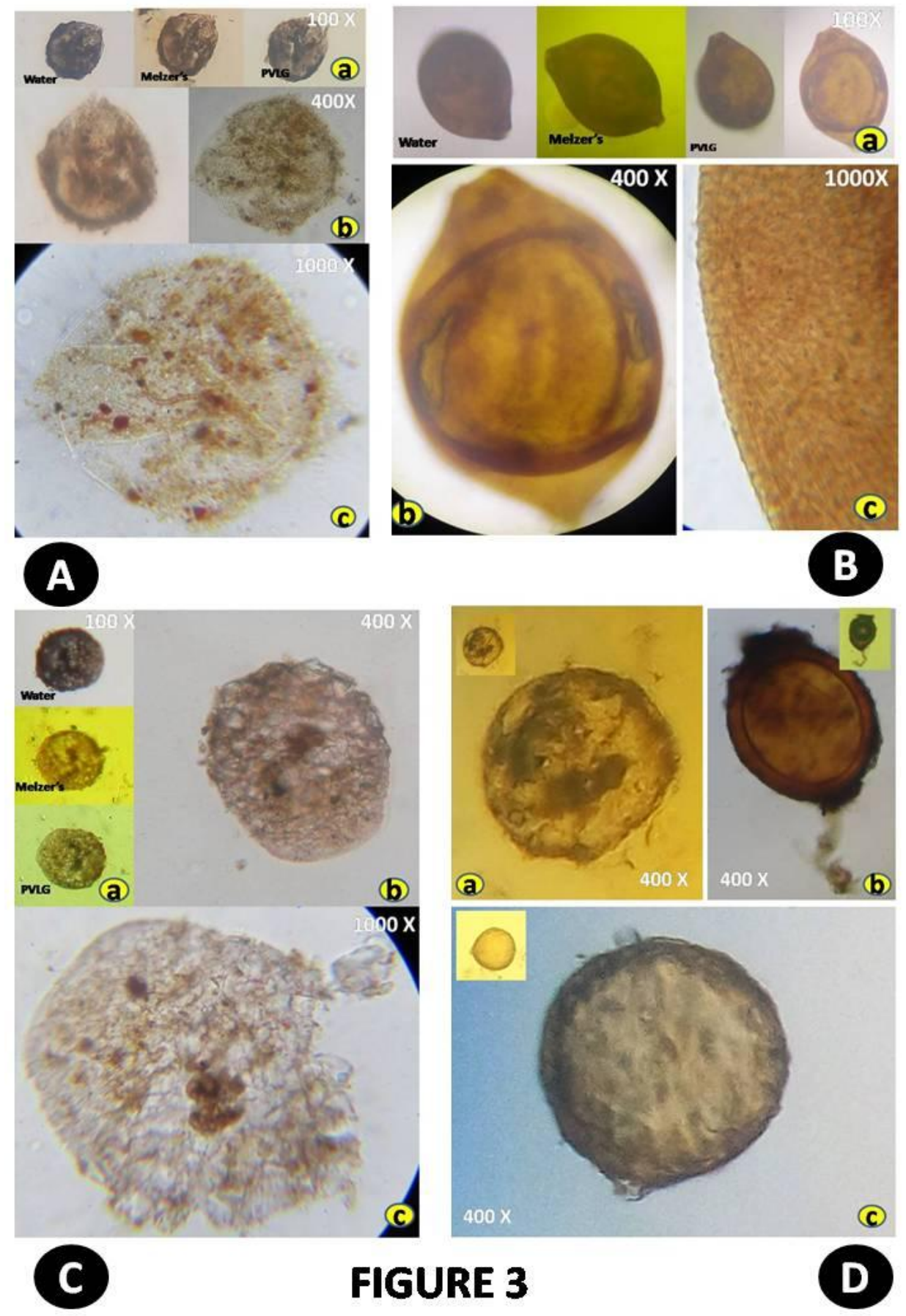


Figure.4A-B AMF spores associated with Eleocharis konkanensis showing morphotype details. Fig.4A Scutellospora arenicola Koske and Halvorson [Fig.4A(a) Spore mounting in different media like Melzer's Reagent and PVLG; Fig.4A(b-c) crushed spore showing spore wall and surface details.; 4A(d) Magnified view showing inner spore wall details.]; and Fig.4B Septoglomus constrictum G.A. Silva and Oehl; [Fig.4B(a-b) Spore mounting in different media like Water, Melzer's Reagent and PVLG; Fig.4B(c) Magnified view showing spore wall and surface hyphae]

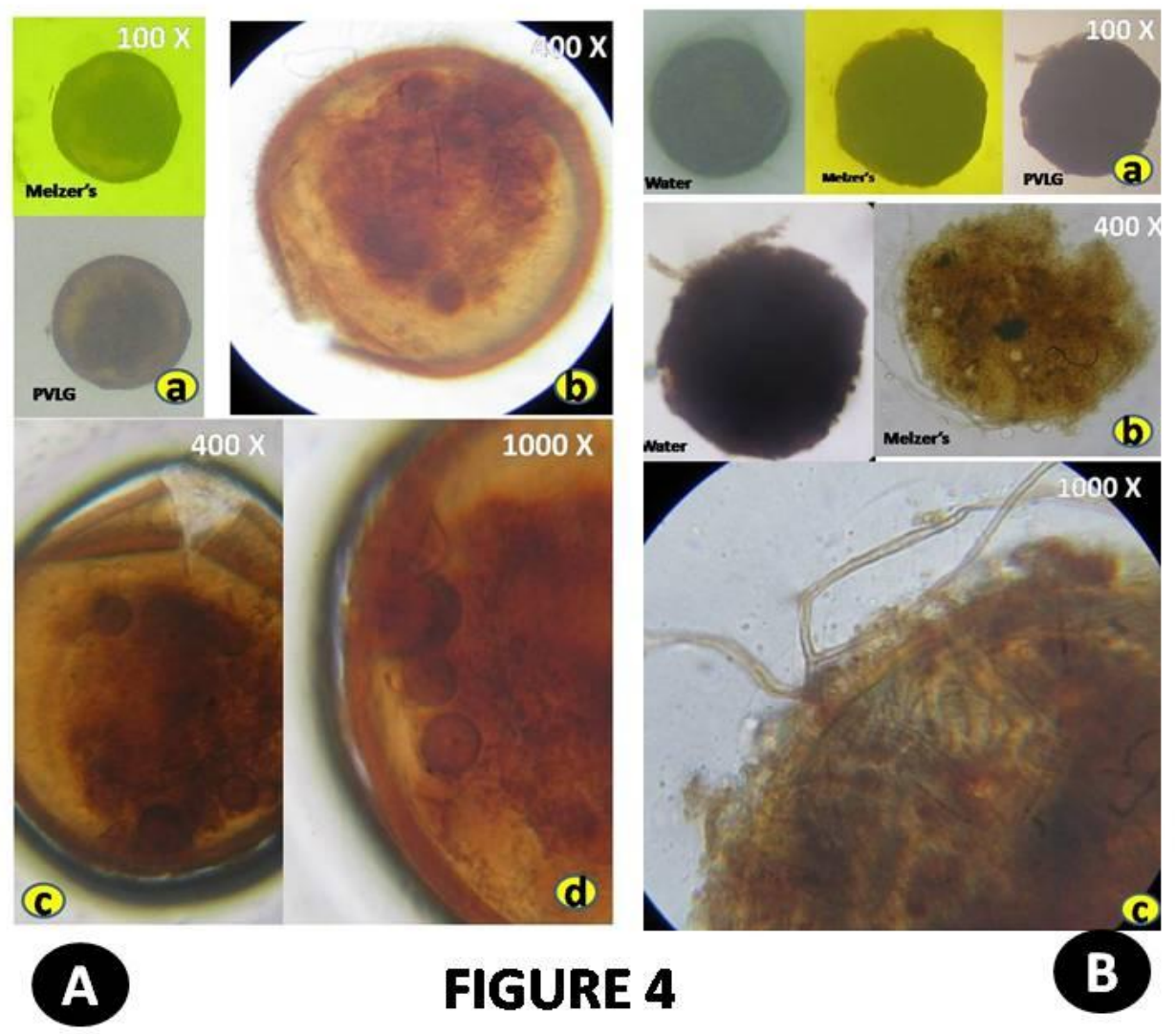

\section{Occurrence intensity $(\mathrm{OI})$}

The occurrence intensity $(O I)$ observed is qualitative expression of corresponding $M C p$ values which are also presented in Table 3 . Analysis of mychorrhizal roots suggests there is great variation found in $O I$ expression for vesicles $(M C p 50 \pm 1.15)$ arbuscles $\left(M C p 21.43 \pm 0.65^{p}\right)$, and hyphae (MCp 98.21 1.70); Thus, arbuscles $O I$ was comparatively poor.In present investigation, although the arbuscular colonization was poor but it is quite common in sedges. According to Muthukumar et al., (2004), "reports on arbuscule occurrence are limited and the nutritional benefits of mycorrhizal association in sedges possessing arbuscules is yet to be ascertained". However, our results showed establishment of vesicular-arbuscular-hyphal VAH type colonization. In fact it was makes general agreement with Jalonen et al., 2013, stated that, total AM colonization is often dominated by hyphal colonisation (Table 3 ).

It was also confirmed with Muthukumar et al., (2004), that, intra radical vesicles and hyphae are frequently encountered AMF structures in sedge roots. During present investigation aggregated form of vesicles $(A v)$, hyphal coiling $(H c)$, chlamydospores 
(Ch) are clearly observed (Figure 1B-C). Furthermore AMF spores have been recorded both attached to roots $i e$ extrararadical spore (ERs) like Muthukumar et al., (1997); Cooke and Lefor (1998) and within roots $i e$ intraradical spore (IRs), as that of Miller et al., (1999) (Figure 1C). These observations decisively demonstrate that endemic sedges like E. konkanensis would greatly improve the persistence and survival of AMF propagules in the soil.

In earlier study range of proportional root length $(\mathrm{cm})$ colonized by AMF was found varied for different species (Table 1) i.e. E. obtusa and E. palustris were colonized 0-0.7 and $\quad 0-0.6 \mathrm{~cm}$ respectively; whereas, arbuscular colonization was $0-0.1$ and $00 \mathrm{~cm}$ respectively, it was lacked of hyphal coiling but showed presence of sepatate endophytes (Hossler (2010). However, our observations on E. konkanensis suggests presence of other fungal endophytes (Ofe) dark septate hyphae (Dsh) (Figure 1D) along with AMF colonization. It is evident that, dark septate fungi can extensively colonizes the roots under such an environmental condition where AMF fail to proliferate (Khon and Stasovski, 1990; Treu et al., 1996). The role of Dsh in most of the plant is unclear but there is growing evidence that these endophytes may play roles similar to those of $\mathrm{AMF}$ in enhancing host growth and nutrition uptake (Barrow and Aaltonen, 2001). It often to see dual colonization of dark septate endophytes with AMF under less extreme environments (Read and Haselwandter, 1981; Bledose et al., 1990; Khon and Stasovski 1990; Väre et al., 1992; Treu et al., 1996). In present report such dual colonization is appeared but AMF colonization is dominating over dark septate endophytes.

In recent study, de la Providencia et al., (2015) performed molecular diversity exploration using high-throughput PCR, cloning and sequencing of $18 \mathrm{~S}$ rDNA on $E$. obtusa spontaneously inhabiting in extremely petroleum hydrocarbon polluted sediments. Results observed were found with unexpected diversity of AMF associated. Hence these associated AMF were considered as potentially important microbial candidates in bioremediation of oil-contaminated soils. Therefore to tap the commercial and environmental potential of sedges like Eleocharis more attention is needed toward the mycorrhizal diversity by using molecular tools along with classical method in AMF research.

\section{Assessement of AM fungal species}

In genus Eleocharis till the date no data is available on AMF species. Hence, present paper provides significant details on AMF species associated with any Eleocharis species ever studied before. In present study total twelve species of AM fungi under four families of Glomeromycetes such as: Acaulosporaceae, Diversisporaceae, Gigasporaceae and Glomeraceae were identified from the lateritic soil samples of $E$. konkanensis distributed over five genera viz., Acaulospora, Diversispora, Scutellospora, Glomus and Sclerocystis. The spores of all 12 species are presented in Table 4. The details of all 12 AMF species spore morphotypes are well illustrated in present paper (Figures 2-4). Amongst the 12 species, genus Acaulospora and Glomus represented six and three species (50\% and 25\%) respectivelly. represented two species $(11.11 \%)$. Whereas, remaining three genera viz., Diversispora and Scutellospora and Septoglomus represented only one species $(8.33 \%)$.

During present work, AM fungal species associated with E. konkanensis are identified up to species level (Table 4). These species are viz., Aculospora dilatata Morton. [ BCA:MH $\mathrm{HSL}_{\mathrm{SL}}$ O1], Acaulospora scrobiculata Trappe [BCA: $\mathrm{MH}_{S S L} \mathrm{O2}$ ], Aculospora spinosa. 
Walker and Trappe [BCA:MH $\left.H_{S L L} 03\right]$, Aculospora sporocarpa Berch [BCA:MH SSL $_{\text {O4] }}$ Acaulospora spp1 [BCA:MH $\left.{ }_{S S L} 05\right], \quad$ Aculospora tuberculata Janos and Trappe [BCA:MH $\left.{ }_{S S L} 06\right]$; Diversispora epigaea (B.A. Daniels and Trappe) C. Walker and A. Schüßler [BCA:MH ${ }_{S S L}$ O7]; Scutellospora arenicola Koske and Halvorson [BCA:MH $\left.H_{S S L} 11\right]$; Glomus albidum C. Walker and L.H. Rhodes [BCA:MH ${ }_{S S L}$ 08], Glomus ambisporum G.S. Sm. and N.C. Schenck [BCA:MH $H_{S S L} 09$, Glomus macrocarpum Tul. and C. Tul.[ BCA:MH $\left.{ }_{S S L} 10\right]$ and Septoglomus constrictum G.A. Silva and Oehl [BCA:MH $\left.{ }_{S S L} 12\right]$. Thus, E. konkanensis is proposed as the first representative of genus Eleocharis ever studied by any Indian mycologist with reference to root colonization followed by spore's identification of AMF at species level.

\section{Spore density and relative abundance}

The total number of AM fungal spores recovered from lateritic rhizospere soil samples of E. konkanensis was 51 and encountered at the rate of 1-9 spores $10^{-1} \mathrm{~g}$ soil. The spore density (S) of all 12 AM fungi were determined and expressed as number of spores per $10 \mathrm{~g}$ of soil of E. konkanensis which is presented in Table 3 .

After analyzing the RA and $\mathrm{S}$ values for native AMF species of $E$. konkanensis $i e$ RAspp $>6 \%$ and $\mathrm{S} \geq 7$ spores the dominant AMF species are Diversispora epigaea (RAspp: 17.647; S:9), Aculospora dilatata and Aculospora scrobiculata (RAspp: 13.725; S:7 each). Whereas, dominant AMF Glomeromycota family recognized after comparing values: RAfam $>40 \%$ and $\mathrm{S} \geq 10$ spores. The dominating AMF Glomeromycota family is Acaulosporaceae. Although, Diversisporaceae is apparently expressed highest number of spores ( 9 spores $10^{-1} \mathrm{~g}$ soil) which is contributed by Diversispora epigaea alone. However, Acaulosporaceae has expressed spores number ranging (2-7 spores $10^{-1} \mathrm{~g}$ soil) but cumulatively 28 spores $10^{-1} \mathrm{~g}$ soil are encountered. It is difficult at present to explain the probable reason for this differential expression of spore numbers by two families. Probably, the inter-generic competition between two genera i.e. Diversispora (single species) vs Aculospora (6 species) could led the underestimating effect over representing family (Diversisporaceae) by Acaulosporaceae. However, to support this hypothesis, such kind of diversified data must be processed from various AMF community associations with different host. At present, we conclude Acaulosporaceae members are dominatingly associated with an endemic sedge $E$. konkanensis from lateritic habitat. Finally, on the basis of in-depth analysis we propose that Eleocharis konkanensis an endemic sedge of Maharashtra is a new mycorrhizal plant to the science.

In present paper, documentary evidences proved that, genus Eleocharis is less studied for AMF colonization in general; more precisely it is poorly investigated with reference to AMF species. Hence, present paper provides significant details on AMF species associated with any Eleocharis species ever studied. Ambiguity of sedges or Cyperaceae members with reference to their mycorrhizal or non-mycorrhizal merit is still unresolved. Because, colonization in sedges may be strongly influenced by variation in environmental conditions. However, based on the numerically available references, currently it can be concluded that Cyperaceae is not strictly a non-mycorrhizal family (Muthukumar et al., 2004). To support it, present report on mycorrhizal nature of an endemic sedge E. konkanensis could stand as one more encouraging evidence. Nevertheless, threatened inhabitants flora of lateritic plateaus from Konkan region is yet to 
investigate for their natural symbionts like mycorrhiza. Hence, inventories are needed for many more such endemic plant species associated with poorly known lateritic soilplant - mycorrhiza interaction.

\section{References}

Anderson, R. C., Liberta, A. E., and Dickman, L. A. 1984. Interaction of vascular plants and vesicular-arbuscular mycorrhizal fungi across a soil moisture-nutrient gradient. Oecologia, 64:111-117.

Aziz T., Sylvia, D. M. and Doren, R. F. 1995. Activity and species composition of arbuscular mycorrhizal fungi following soil removal. Ecological Applications, 5:776-784.

Barrow, J. R. and Aaltonen, R. E. 2001. Evaluation of the internal colonization of Atriplex canescens (Pursh) Nutt. roots by dark septate fungi and the influence of host physiological activity. Mycorrhiza, 11: 199-205.

Beck-Nielsen, D., and Madsen, T. V. 2001. Occurrence of vesicular-arbuscular mycorrhiza in aquatic macrophytes from lakes and streams. Aquatic Botany, 71:141-148.

Bledose, C., Klein, P., and Bliss, L. C. 1990. A survey of mycorrhizal plants on Truelove Lowland, Devon Island, N.W.T. Can J Bot 68:1848-1856

Bohrer, K. E., Friese, C. F., and Amon, J. P. 2004. Seasonal dynamics of arbuscular mycorrhizal fungi in differing wetland habitats. Mycorrhiza, 14:329-337.

Borude, D. B., Chandore1, A.N., Gholave, A. R. and Yadav S. R. 2016.. Eleocharis neglecta (Cyperaceae), A new species from Konkan region of Maharashtra, India. Bangladesh J. Plant Taxon. 23(2): 91-96.

Brundrett, M., Bougher, N., Dell, B., Grove, T., and Malajczuk, N. 1996. Working with Mycorrhizas in Forestry and Agriculture. ACIAR Monograph 32, Pirie Printers, Canberra, Australia, pp. 374.

Chandore, A.N., Borude, D.B., Kambale, S. S. and Yadav, S. R. 2016. Eleocharis konkanensis, a new species of Cyperaceae from the Konkan region of Western Ghats, India. Phytotaxa 252 (2): 154-158.

Chaubal, R., Sharma, G. D., and Mishra R. R. 1982. Vesicular arbuscular mycorrhiza in subtropical aquatic and marshy plant communities. In, Proceedings of the Indian Academy of Sciences, Section B, 91: 69-77.

Clayton, J. S., and Bagyaraj. 1984. Vesiculararbuscular mycorrhizas in submerged aquatic plants of New Zealand. Aquatic Botany, 19:251-262,

Cooke, J. C., and Lefor, M. W. 1998. The mycorrhizal status of selected plant species from Connecticut wetlands and transition zones. Restoration Ecology, 6:214-222.

Cornwell, W. K., Bedford, B. L., and Chapin, C. T. 2001. Occurrence of arbuscular mycorrhizal fungi in a phosphoruspoor wetland and mycorrhizal response to phosphorus fertilization. Am J Bot 88:1824-1829.

Dandan, Z., Zhiwei, Z. 2007. Biodiversity of arbuscular mycorrhizal fungi in the hot dry valley of the Jinsha River, southwest China. Appl. Soil Ecol., 37: 118-128.

de la Providencia, I. E., Stefani, F. O. P., Labridy, M., St-Arnaud M., and Hijri, M. 2015. Arbuscular mycorrhizal fungal diversity associated with Eleocharis obtusa and Panicum capillare growing in an extreme petroleum hydrocarbon-polluted sedimentation basin FEMS Microbiology Letters, 362(12): 1-9. doi: 10.1093/femsle/fnv081 
Dowding, E. S. 1959. Ecology of Endogone. Transactions of the British Mycological Society, 42: 449-457.

Fontenla, S., Puntieri J., and Ocampo, J. A. 2001. Mycorrhizal associations in the Patagonian steppe, Argentina. Plant Soil 233:13-29.

Gaur, A., Adholeya, A. 1994. Estimation of VAMF spores in soil: a modified method, Mycorrhiza News, 6: 10-11.

Gerdemann, J. W., Nicolson, T. H. 1963. Spores of mycorrhizal Endogone species extracted from soil by wet sieving and decanting. Trans. Br. Mycol. Soc., 46: 235-244.

Govaerts, R. 2016. World Checklist of Cyperaceae, <http://apps.kew.org/ wcsp/qsearch.do>. Royal Botanic Gardens, Kew. Retrieved on 20th April 2018.

Hall, I. R., and Fish, B. J. 1979, A key to the Endogonaceae. Trans. Br. Mycol. Soc., 73, 261-270.

Harley, J. L. and Harley, E. L.1987a. A check-list of mycorrhiza in the British flora. New Phytologist, 105:1-102.

Harley, J. L. and Harley, E. L.1987b. A check-list of mycorrhiza in the British flora-addenda, errata and index. New Phytologist, 107:741-749.

Hossler, K. 2010. Nutrient Cycling and the Role of Arbuscular Mycorrhizae in Created and Natural Wetlands of Central Ohio. PhD Thesis Ohio State University

Jackson, M. L. 1967. Soil chemical analysis, Prentice Hall of Indian Private Limited, New Delhi. pp.1-498.

Jalonen, R., Timonen, S., Sierra, J., and Nygren, P. 2013. Arbuscular mycorrhizal symbioses in a cut-andcarry forage production system of legume tree Gliricidia sepium and fodder grass Dichanthium aristatum. Agroforest Syst, 87:319-330. DOI 10.1007/s10457-012-9553-1
Khan, A. G., and Belik, M. 1995. Mycorrhiza: Structure, Function, Molecular Biology and Biotechnology, chapter Occurrence and ecological significance of mycorrhizal symbiosis in aquatic plants, Springer-Verlag, 1st edition, pp. 747.

Khon, L. M., and Stasovski, E., 1990. The mycorrhizal status of plants at Alexandra Firod, Ellesmere Island, Canada, a high arctic site. Mycologia 82:23-35.

Miller, R. M., Smith, C. I., Jastrow, J. D., and Bever, J. D. 1999. Mycorrhizal status of the genus Carex (Cyperaceae). Am $J$ Bot, 86:547-553.

Mujaffar, S., Chandore, A. N., and Yadav, S. R. 2014. Eleocharis khandwaensis sp. nov. (Cyperaceae) from the Madhya Pradesh, India. Nordic Journal of Botany 32: 710-712.

Muthukumar, T. 1996. Studies on the ecology and taxonomy of vesicular arbuscular mycorrhizal fungi from Western Ghats, southern India. PhD Thesis, Bharathiar University, Coimbatore, Tamil Nadu, India.

Muthukumar, T., and Udaiyan, K. 2000. Arbuscular mycorrhizas of plants growing in the Western Ghats region, southern India. Mycorrhiza, 9:297313.

Muthukumar, T., Udaiyan, K., Karthikeyan, A., Manian S. 1997. Influence of native endomycorrhiza, soil flooding and nurse plant on mycorrhizal status and growth of purple nutsedge (Cyperus rotundus L.). Agric Ecosyst Environ, 61:51-58.

Muthukumar, T., Udaiyan, K., and Shanmughavel, P. 2004. Mycorrhiza in sedges - an overview Mycorrhiza. 14:65-77.

Olsen, S. R., Cole, C. V., Watanabe, F. S., and Dean, L. A. 1954. Estimation of available phosphorus in soils by 
extraction with sodium bicarbonate. USDA Circ. No. 939. U.S. Dept. Agric. Washington, D.C.

Pacioni, G. 1992. Wet - sieving and decanting technique for the extraction of spores of vesicular arbuscular mycorrhizal fungi, Meth. Microbiol, 22, 317-322.

Pedersen, O., 2002. Allelopathy - chemical warfare between aquatic plants. The Aquatic Gardener 15(3): 9-18.

Phillips, J. M., and Hayman, D. S. 1970. Improved procedure for clearing roots and staining parasitic and vesicular arbuscular mycorrhizal fungi for rapid assessment of infection, Trans. Br. Mycol. Soc., 55: 158-161.

Piper, C. S. 1966. Soil and Plant Analysis, (Hans Publishers, Bombay). pp 368.

Ragupathy, S., Mahadevan, A., 1993. Distribution of vesicular arbuscular mycorrhizae in the plants and rhizosphere soils of the tropical plains, Tamil Nadu, India. Mycorrhiza, 3:123-136.

Ragupathy, S., Mohankumar, V., and Mahadevan, A. 1990. Occurrence of vesicular-arbuscular mycorrhizae in tropical hydrophytes. Aquat Bot, 36:287-291.

Read, D. J., Haselwandter, K. 1981. Observations of the mycorrhizal status of some alpine plant communities. New Phytol 88:341-352.

Schenk, N. C., Perez, Y. 1990. Manual for the identification of VA - Mycorrhizal fungi, third edition. (University of Florida, Gainesville, Florida) pp. 249.

Silva, G. A. D., Santos B. A. D., Alves, M. V., and Maia L. C. 2001 Arbuscular mycorrhiza in species of Commelinidae (Liliopsida) in the state of Pernambuco (Brazil). Acta Bot Bras, 15:155-165.

Smith, S. E., and Read, D. J. 2008. Mycorrhizal Symbiosis. 3rd edition,
(London, UK: Academic Press,) pp. 800.

Søndergaard, M., and Laegaard S.. 1977. Vesicular-arbuscular mycorrhiza in some aquatic vascular plants. Nature, 268:232-233.

Tester M., Smith, S. E., and Smith, F. A. 1987. The phenomenon of "nonmycorrhizal" plants. Can J Bot 65:419-431.

Thoen, D. 1987. First observations on the occurrence of vesicular-arbuscular mycorrhizae (VAM) in hydrophytes, hygrophytes, halophytes and xerophytes in the region of Lake Retba (Cap-Vert, Senegal) during the dry season. M'emoires de la Soci'et'e Royale de Botanique de Belgique, 9:60-66.

Thormann, M. N., Currah, R. S., and Bayley, S. E. 1999. The mycorrhizal status of the dominant vegetation along a peatland gradient in southern boreal Alberta, Canada. Wetlands 19:438450.

Treu, R., Laursen, G. A., Stephenson, S. L., Landolt, J. C., and Densmore, R. 1996. Mycorrhizae from Denali National Park and Preserve, Alaska. Mycorrhiza, 6:21-29.

Turner, S. D., Amon, J. P., Schneble, R. M. and Friese C. F. Mycorrhizal fungi associated with plants in ground-water fed wetlands. Wetlands, 20:200-204, 2000.

van Reeuwijk, L. P. 2002. Procedures for soil analysis: Technical paper-9; sixth edition, International Soil Reference And Information Centre Publishers, (P.O. Box 353, 6700 AJ Wageningen, The Netherlands), pp. 1-120.

Väre, H., Vestberg, M., and Eurola, S. 1992. Mycorrhiza and rootassociated fungi in Spitsbergen. Mycorrhiza 1:93-104.

Wadoodkhan, M. A. 2015. Cyperaceae of Western Ghats, West Coast and 
Maharashtra. (Dattsons Publishers, Nagpur), pp. 126-148.

Walkley, A., and Black, I. A. 1938. An examination of Degtjareff method for determining soil organic matter and a proposed modification of the chromic acid titration method. Soil Sci., 37: 2937.

Wang B. and Qiu, Y. L. 2006. Phylogenetic distribution and evolution of mycorrhizas in land plants. Mycorrhiza, 16:299-363.
Weishampel, P. A., and Bedford, B. L. 2006. Wetland dicots and monocots differ in colonization by arbuscular mycorrhizal fungi and dark septate endophytes. Mycorrhiza, 16: 495-502. Wooten, J. W., and S.D. Elakovich. 1991. Comparisons of potential allelopathy of seven freshwater species of spikerushes (Eleocharis). Journal of Aquatic Plant Management 29:12-15.

\section{How to cite this article:}

Vishal R. Kamble, Sonali S. Lanjekar, Yadvendradatta R. Yadav, Meghana M. Kolekar, and Arun N. Chandore. 2018. A New Record: Incidence of Arbuscular Mycorrhizal Fungi (AMF) in Eleocharis konkanensis an Endemic Sedge of Maharashtra (India). Int.J.Curr.Microbiol.App.Sci. 7(05): 2243-2258. doi: https://doi.org/10.20546/ijcmas.2018.705.261 